\title{
AUTOVACUUM BRAZING IN REPAIR OF COPPER PANELS OF MCCB MOULDS
}

\author{
G.M. GRIGORENKO, A.L. PUZRIN, M.G. ATROSHENKO, \\ M.A. POLESHCHUK, A.V. SHEVTSOV and I.A. MOSSOKOVSKAYA \\ E.O. Paton Electric Welding Institute, NASU \\ 11 Bozhenko Str., 03680, Kiev, Ukraine. E-mail: office@paton.kiev.ua
}

\begin{abstract}
Using models the possibility of repair of worn-out flat panels of machines of continuous casting of billets (MCCB) moulds by autovacuum brazing of restoration copper layer was tested. The brazed joint was produced between two copper plates without defects in the form of pores and cracks. The tensile strength of copper brazed joint for separation between layers was investigated, and also the bend tests were performed. Thermal resistance of the brazed joint was evaluated. The obtained results allow the method of autovacuum brazing to be recommended for repair of flat panels of the moulds. 12 Ref., 6 Figures.
\end{abstract}

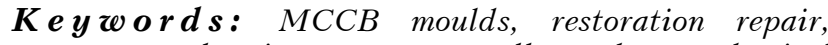
autovacuum brazing, seams, metallography, mechanical properties, thermal resistance

At present the main amount of the melted steel is undergone casting in the machines of continuous casting of billets (MCCB). The molten steel is poured into special devices: water-cooled moulds, the inner cavity of which has a section, corresponding to the section of the future billet. Walls of the moulds, faced inwards, are manufactured of copper. Due to intensive dissipation of heat by the cooling water the molten metal is solidified on the inner wall of the mould. At the same time, steel crust, making an external surface of the billet being melted, is formed around the entire perimeter of its cavity. During the process of the billet withdrawal the hard steel crust is moved along the mould copper wall, thus leading to the non-uniform wear of the latter and formation of different long defects on it [1].

These defects are formed more intensively in melting out of rectangular-section billets in MCCB of a radial type. Moulds for melting of these billets are assembled of separate flat panels with a working wall of copper, alloyed by a small amount of silver or chromium. Area of some of them can reach one square meter [2].

For removal of defects the copper walls of mould panels should be subjected to periodical machining. The thinning of walls after multiple treatments causes the hazard of damage of watercooling channels and coming out of order of the whole mould. Therefore, the task of restoration of the initial sizes of copper walls of the flat panels is urgent.

Electric arc surfacing of worn-out copper walls does not allow solving this problem as far as at a local heating of large copper plates, possessing high heat conductivity, their non-admissible distortion, incapable to correction, is occurred [3].

A procedure was developed for deposition of a restoration layer of copper on copper plate by using the method of friction stir welding [4]. This method is rather efficient in repair of separate regions of mould walls, but its application on large surfaces requires also the additional measures for reducing distortion of the plates being repaired.

It is possible to avoid distortion of the mould walls by brazing-on of copper sheet of a required thickness to them over the entire surface. In this case the heating and cooling of the product occur uniformly in the whole volume, not causing its deformation.

To provide the effective operation of the MCCB mould with repaired copper walls, it is necessary to minimize an additional heat resistance during the brazing process, which is introduced by brazing alloy layer into the coefficient of heat transfer from the molten steel to the cooling water through a multilayer wall. This coefficient will be minimum at keeping the following conditions: it is necessary to have a defectless layer of a minimum thickness over all the surface of copper sheets being joined, and heat conductivity coefficient of the brazing alloy should be close to the appropriate copper coefficient.

Among all the known types of brazing the most quality joint of large-area surfaces is produced by the method of autovacuum brazing (AVB). The AVB technology is based on a spontaneous cleaning of metal surfaces from oxide films, forming an air-tight gap, and next its fill- 
ing with a molten brazing alloy during the product heating for brazing. This process occurs due to diffusion of oxygen from the air-tight gap through an oxide film inside the hot metal. Here, an autonomous vacuum is formed in the gap. The fracture of oxide films in air-tight gap is started after reaching the vacuum of a definite degree. Time of cleaning of metal surfaces from oxide films can be significantly reduced by degassing of the air-tight gap before heating [5].

Using this method in industry under the conditions of «Azovmash» plant, the steel bimetal billets of up to $4 \mathrm{~m}^{2}$ area are successfully manufactured [6]. However, there is no information in literature about AVB application for joining of copper sheets between each other.

The aim of the present work was in experimental verification of the possibility of producing the quality joint of copper sheets by AVB and application of this method for restoration of sizes of MCCB mould copper walls.

To guarantee the brazing quality at any region of joining of large-area flat products it is rational to use the AVB diagram at a horizontal position of the product being brazed. Here, brazing alloy in the form of a foil should be placed beforehand between the copper sheets over the whole area of contact. Experimental works were carried out by brazing of $80 \times 80 \mathrm{~mm}$ packets.

The packets, prepared for brazing, were mounted into special cassettes, creating a closed volume (Figure 1). Material for manufacture of cassettes was a thin steel sheet, which at the brazing temperature provided the compression of the packet at atmospheric pressure uniformly over the entire surface. The packets were made of three layers: base metal simulating the mould wall, restoration layer and brazing alloy between

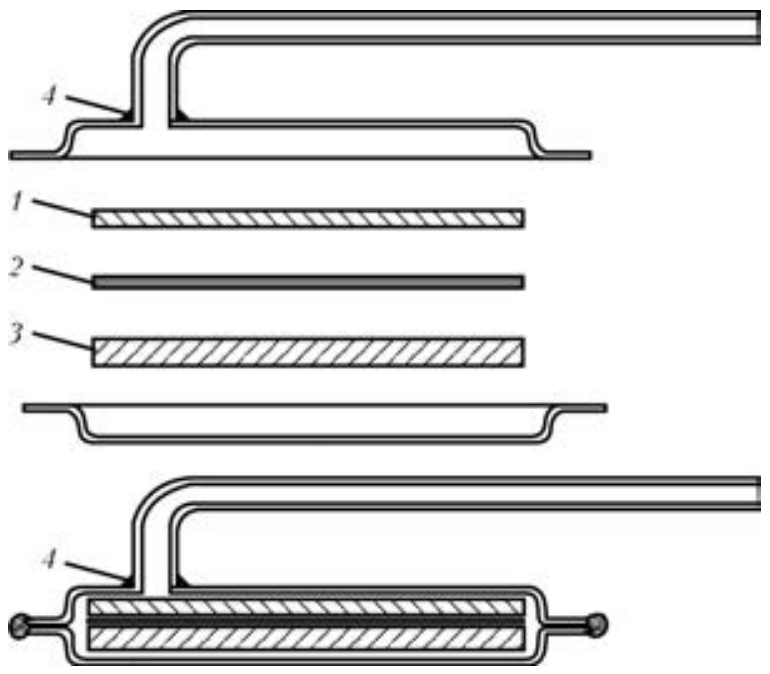

Figure 1. Assembly of cassette for AVB of specimens: 1 restoration layer; 2 - brazing alloy; 3 - base metal; 4 technological welds them. As a base metal the $7 \mathrm{~mm}$ thick copper of M-1 grade was used, and the restoration layer of copper of the same grade had $2 \mathrm{~mm}$ thickness. The brazing alloy was a $0.2 \mathrm{~mm}$ thick foil, placed in two layers.

The filled cassettes were welded around the perimeter by argon-arc welding with a vacuumtight weld. The branch pipe was welded-in to the cassette for degassing. The prepared cassettes were placed on the table in a muffle furnace, the branch pipe was taken outside, a forevacuum pump equipped with a manovacuummeter was connected to it.

Before brazing the rarefication of $5 \cdot 10^{-2} \mathrm{~mm}$ $\mathrm{Hg}$ was created inside the cassette and the valve was shut. The furnace was heated up to the required temperature of brazing with $30 \mathrm{~min}$ isothermal holding. Cassettes were cooled together with the furnace. During the whole brazing process the rarefication inside the cassette was controlled by a manovacuummeter. The brazed packets were cut into specimens for metallographic examinations and mechanical tests.

To select the optimum chemical composition of the brazing alloy, taking into account its temperature of melting and coefficient of heat conductivity, the experiments were carried out by using the foil of two different grades: brass L63 (brazing temperature is $950-960{ }^{\circ} \mathrm{C}$ ) often used for copper brazing, and beryllium bronze $\mathrm{BrB} 2$ (temperature of melting is $1030-1040{ }^{\circ} \mathrm{C}$ ) having a coefficient of heat conductivity close to that of copper.

During metallographic examinations of nonetched brazed joints on the specimens with brass L63 brazing alloy over the entire length of the seam [7] the elongated pores of length from 100 up to $330 \mu \mathrm{m}$ and width from 20 up to $50 \mu \mathrm{m}$, located close to the seam middle, are observed. There are cracks between some pores (Figure 2, a). The formation of pores in the joint brazed using L63 alloy is explained by zinc evaporation during brazing [8]. The zinc evaporation is confirmed by increase in indications of the manovacuummeter at increase of the furnace temperature above $500{ }^{\circ} \mathrm{C}$. At the same time, the place of joining of base metal and restoration layer is almost invisible, pores and cracks are absent on the non-etched section with BrB2 brazing alloy (Figure 2, b).

Figure 3 shows structures of brazed joints, revealed by etching in $50 \%$ solution of nitric acid. On the specimen with L63 brazing alloy (Figure 3,a) there are common grains of seam with base metal and restoration layer. Thickness of brazing alloy layer is approximately $250 \mu \mathrm{m}$, 
microhardness is 740-800 $\mathrm{MPa}$. On the specimen, brazed with BrB2 alloy (Figure $3, b$ ), the layer of brazing alloy of $90 \mu \mathrm{m}$ thickness was observed having common grains with base metal on separate regions. On both sides of the seam, as well as in the seam itself, the non-metallic inclusions of a rounded shape of 5-60 $\mu \mathrm{m}$ size were observed. Microhardness of the brazing alloy layer is $1080 \mathrm{MPa}$, while that of base metal and restoration layer is $740 \mathrm{MPa}$. The smooth change in microhardness can be explained by the diffusion of beryllium of the brazing alloy inside the copper. The base metal and restoration layer of all the specimens have the structure, typical of the annealed copper.

Information about structure and sizes of the brazing alloy layer and diffusion zones, obtained during metallographic examinations, can be used for determination of their thermal resistance and evaluation of its contribution into coefficient of heat transfer from the molten metal to the cooling water through a multilayer wall of the mould. The thermal resistance of this wall $R_{\Sigma}$ consists of a sum of resistances of layers included into it, each of which is determined by a quotient from division of layer thickness $d(\mathrm{~m})$ by coefficient of heat conductivity of its material $\lambda$ $\left(\mathrm{W} /\left(\mathrm{m} \cdot{ }^{\circ} \mathrm{C}\right)\right)$. As applied to the copper wall of the mould, restored by brazing, the value of thermal resistance is determined by the following expression:

$$
\begin{aligned}
& R_{\Sigma}=R_{\mathrm{m}}+R_{\mathrm{s}}+R_{\mathrm{z}}=d_{\mathrm{m}} / \lambda_{\mathrm{m}}+ \\
& +d_{\mathrm{s}} / \lambda_{\mathrm{s}}+d_{\mathrm{z}} / \lambda_{\mathrm{z}}\left({ }^{\circ} \mathrm{C} \cdot \mathrm{m}^{2} / \mathrm{W}\right),
\end{aligned}
$$

where $R_{\mathrm{m}}, R_{\mathrm{s}}, R_{\mathrm{z}}$ is the total thermal resistance of all the layers, respectively; $\lambda_{\mathrm{m}}=$ $=393 \mathrm{~W} /\left(\mathrm{m} \cdot{ }^{\circ} \mathrm{C}\right)$; coefficient of heat conductivity of L63 brazing alloy layer is $\lambda=105$, for BrB2 $\lambda=352 \mathrm{~W} /\left(\mathrm{m} \cdot{ }^{\circ} \mathrm{C}\right) ; R_{\mathrm{z}}$ is the total thermal resistance of the diffusion zones, the heat conductivity of which can be accepted averaged between those of copper and brazing alloy [9].

The coefficients of heat conductivity of materials, used by us as brazing alloys, are the values of one order with coefficient of heat conductivity of copper. At the same time, the thicknesses of layer of the brazing alloy and diffusion zones, measured in tens or hundreds of microns, are by two-three orders lower than the total thick of copper layers, measured in tens of millimeters. Thus, the thermal resistance of the interlayer of brazing alloy and diffusion zones will be by the same two-three orders lower than the resistance of copper layers. Therefore, when calculating the thermal resistance of the restored copper wall of the mould the additional resistance, created by

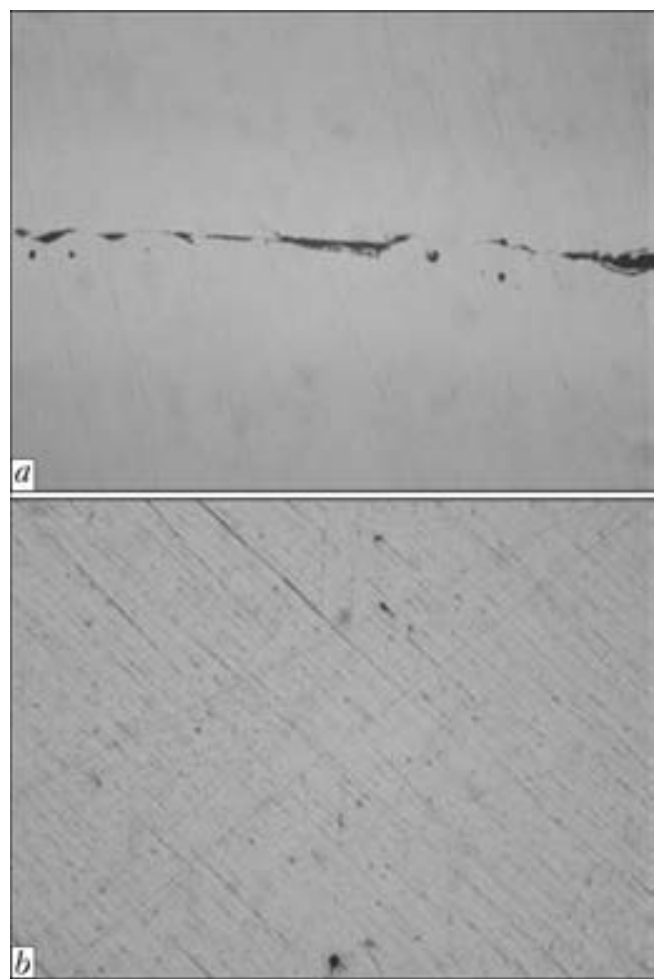

Figure 2. Structure $(\times 200)$ of non-etched specimens after AVB of copper: $a-\mathrm{L} 63 ; b-\mathrm{BrB2}$ brazing alloy

defectless brazed joint, produced by AVB method, can be not taken into account.

At the same time, the defects in the interlayer of the brazing alloy in the form of pores, cracks, and lack of brazing in particular, can create definite disturbances to the heat flow through a multilayer wall. At concentration of such defects in

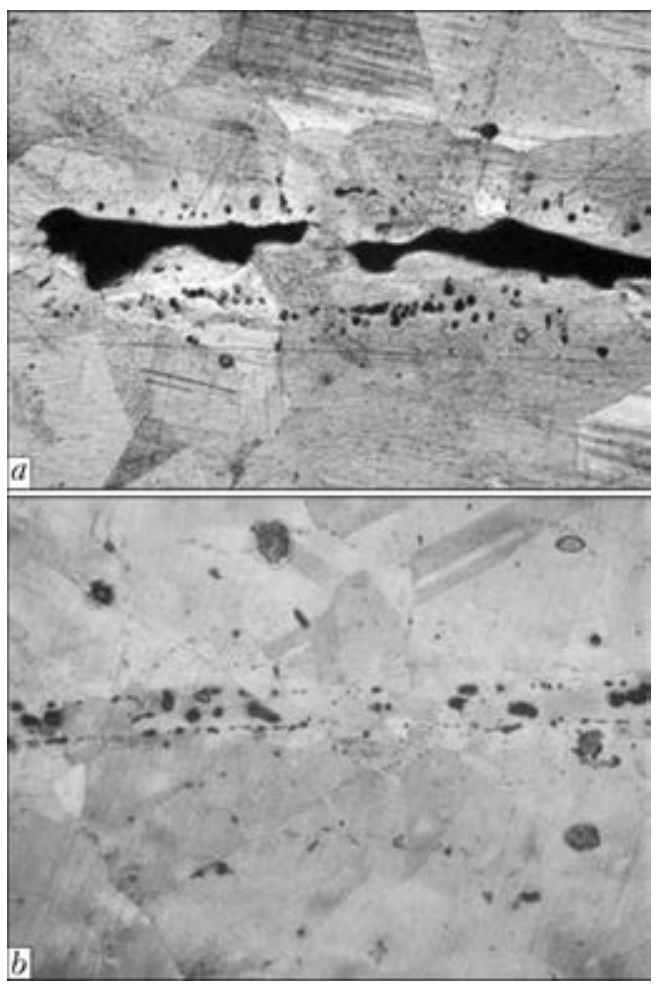

Figure 3. Structure $(\times 200)$ of copper joints produced by AVB method: $a-$ L63; $b-$ BrB2 brazing alloy 


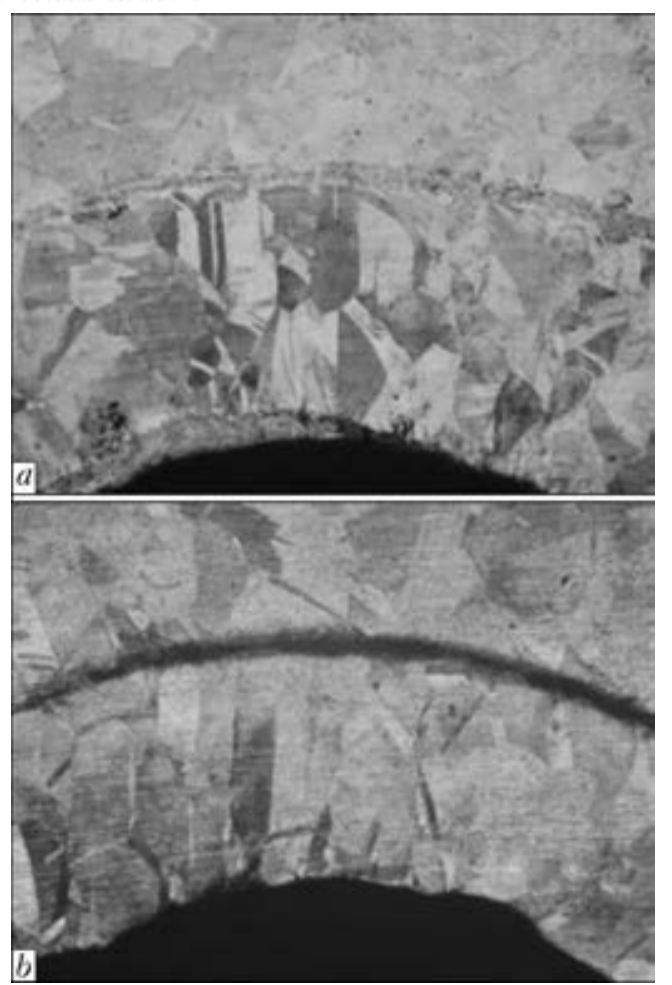

Figure 4. Microsections $(\times 25)$ of bending places of brazed joints: $a-\mathrm{L} 63 ; b-\mathrm{BrB} 2$ brazing alloy

local area of the brazed joint a remarkable reduction in heat dissipation from the restoration layer may occur and, as a consequence, the increase in its temperature at this place. At a definite value of the heat flow from the molten metal to the mould multilayer wall the growth in temperature of the restoration layer can lead to its deformation at that place and even to separation from the base metal. Thus, during the restoration repair of copper walls of the moulds it is necessary to provide technologically defect-free brazing.

During operation of the mould with copper walls, repaired by AVB method, the seam, connecting the base metal and restoration layer, should have the strength, preventing the separation of the latter in effect of forces of shear and bending. In addition, to decrease the wear the surface of the restored layer should have the hard-

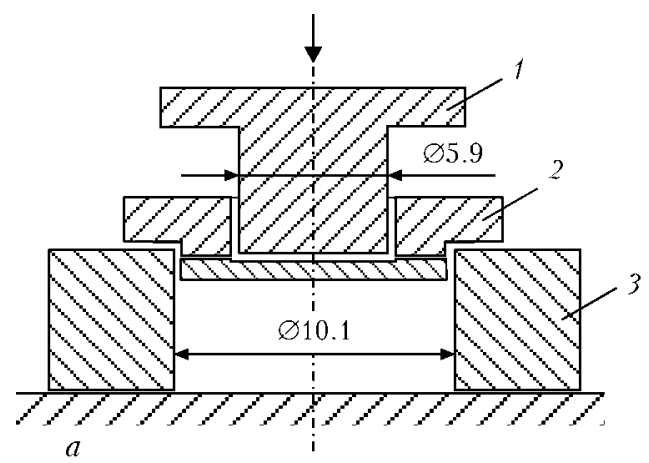

Figure 5. Scheme of pull tests $(a)$ of brazed joint specimen $(b): 1-$ punch; 2 - specimen; $3-$ matrix; $4-$ base metal; 5 - seam; 6 - restoration layer

ness close to that of copper surface before the repair. The specimens were tested for separation of the restoration layer and bending of the brazed joint, and also the microhardness of surface of the restoration layer after brazing was measured.

For bending test across the entire surface of the brazed joint the special specimens of $80 \times$ $\times 10 \mathrm{~mm}$ size were cut out, which were bent for $90^{\circ}$ angle by restoration layer inside. Separations of the restoration layer from the base metal on the specimens using brazing alloys L63 and BrB2 were not observed (Figure 4).

The mechanical properties of the produced brazed joints were evaluated by the tensile pull strength between the layers. The tests like those are not regulated by the GOST, therefore, they were performed using scheme, presented in Figure $5, a$, on specimens, the sizes of which are indicated in Figure 5, $b$ [10].

For verification and comparison of results, obtained according to the above-mentioned scheme, the monolithic specimens of the same sizes manufactured from the same copper sheet, which was used for brazing, were tested. The tensile pull strength of the monolithic specimen was $450 \mathrm{MPa}$, that corresponds to that of the wrought copper M1 [11]. Thus, the scheme of tests, used by us, can be considered acceptable.

The average value of tensile pull strength of specimens, brazed by brass L63, was $240 \mathrm{MPa}$, and that of specimens brazed by bronze BrB2 was $530 \mathrm{MPa}$. The lower value of the tensile pull strength of specimens brazed by L63, as compared with monolithic specimens, is explained by the pores presence in the seam. At the same time, the higher values of tensile pull strength, obtained in brazing of copper by bronze BrB2, can be explained by the absence of defects in the brazed joint, having the common grains with copper, and also by the presence of diffusion zone, hardened by beryllium, in the copper.

By analyzing the results of metallographic investigations, mechanical tests and evaluation of

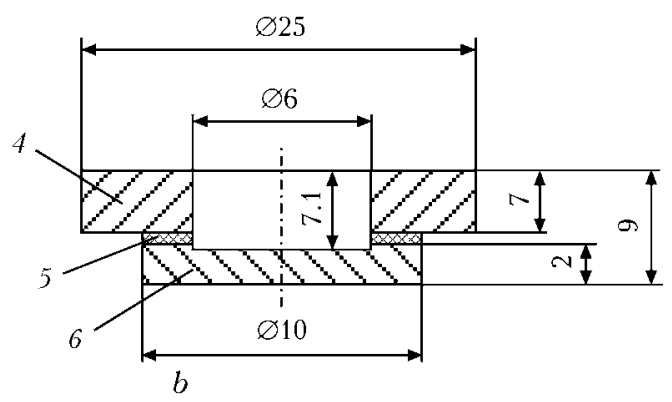


values of thermal interlayer of brazing alloys it is possible to recommend the brazing alloy of beryllium bronze $\mathrm{BrB2}$ in the form of foil for restoration repair by AVB method of flat panels of the MCCB moulds.

Due to change in copper structure during heating for brazing, the hardness of base metal and restoration layer before and after AVB were determined. The initial values of copper hardness were in the ranges of 579-606 MPa, that corresponds to the hardness of the wrought and annealed copper [11]. After AVB the copper hardness decreased negligibly to 530-550 $\mathrm{MPa}$.

The resistance of MCCB moulds, consisting of flat copper panels, does not often exceed 100 melts [2], while the resistance of moulds with protective coating - thin layer of material having the higher strength, is 10 times increased [12]. In this connection it is desirable to deposit the protective coating on the copper surface faced inside the mould. This coating may be a thin stainless steel sheet, brazed-on to the restoration layer of copper. The prior experience (Figure 6) shows a feasibility of producing for single heating the multilayer brazed joint, including restoration layer of copper and wear-resistant coating of thin stainless steel sheet.

\section{Conclusion}

It was shown experimentally that AVB method can be applied for producing the quality joint of copper sheets of large area in plane and is challenging in repair of panels of MCCB moulds. The defect-free brazed joints with high mechanical characteristics were produced by AVB method using foil of bronze BrB2 as the brazing alloy. Due to small thickness of the interlayer and high heat conductivity of the brazing alloy, its thermal resistance can be neglected at thermal design of the mould. The possibility of deposition of the protective coating simultaneously with deposi-

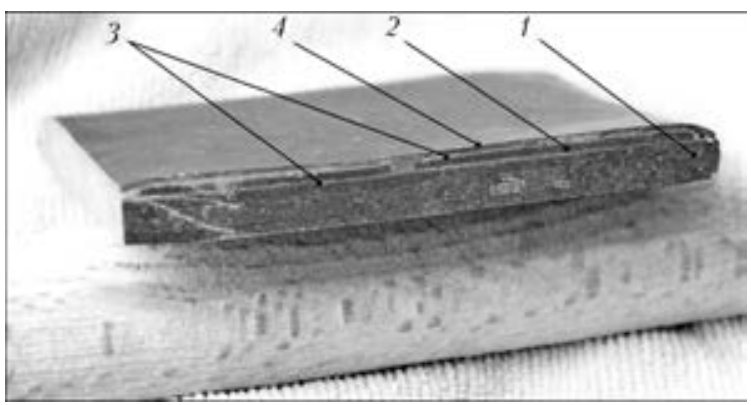

Figure 6. Multilayer joint produced per one heating by AVB method: 1 - base layer; 2 - restoration layer; 3 seams; 4 - wear-resistant coating

tion of the restoration layer in the mould repair is shown experimentally.

1. Evteev, D.P., Kolybalov, I.N. (1984) Continuous casting of steel. Moscow: Metallurgiya.

2. Markushin, A.A., Kuklev, A.V., Ajzin, Yu.M. et al. (2005) Radial slab mold with slot channels and nickel coating of walls, 38-41. Moscow: Metallurg.

3. Abramovich, V.R. (1988) Fusion welding of copper and alloys on its base. Moscow: Mashinostroenie.

4. Nikityuk, Yu.N., Grigorenko, G.M., Zelenin, V.I. et al. (2013) Technology of reconditioning repair of slab molds of MCCB with friction stir welding method. Sovr. Elektrometallurgiya, 3, 51-55.

5. Puzrin, L.G., Bojko, G.A., Atroshenko, M.G. (1975) Autovacuum brazing. Kiev: Znanie.

6. Puzrin, L.G., Atroshenko, M.G., Peshcherin, I.G. et al. (1984) Autovacuum brazing of ultra-thick wall vessels of up to hundred tons mass. In: Problems of welding and special electrometallurgy, 76-77. Kiev: PWI.

7. GOST 17325-79: Soldering and tinning. Main terms.

8. (1975) Reference book on soldering. Ed. by S.N. Lotsmanov at al. Moscow: Mashinostroenie.

9. Yong, H. (1979) Basic formulae and data on heat exchange for engineers. Moscow: Atomizdat.

10. Mardyan, M.G., Ryabchikov, E.A., Epshtejn, G.N. (1979) Procedure for determination of cohesive strength of bimetal layers. Zavod. Laboratoriya, 8, 757-759.

11. Keloglu, Yu.P., Zakharievich, K.M., Kartashevskaya, M.A.' (1977) Metals and alloys: Refer. Book.

12. Masato, T. (2009) Molds of machines of continuous steel casting of Mashima Kosan. In: Proc. of Int. Sci.-Pract. Seminar on Electrocladding and Thermal Spraying (Ekaterinburg, 2009), 1-19.

Received 16.04.2015 